\title{
REPERTORIO BIBLIOGRAFICO SOBRE EL PROCESO CONSTITUYENTE ESPAÑOL (I)
}

Tomando pie en el repertorio que presentara sobre la transición en el número 4 de esta misma revista, intento ahora ir algo más allá, dando cuenta con éste del proceso mismo en virtud del cual el régimen anterior ha venido sustituyéndose por la actual Monarquía Parlamentaria. No se trata, por consiguiente, de ordenar una temática concreta cuanto de radiografiar bibliográficamente un conjunto heterogéneo de éstas que, simultáneamente, se ven afectadas en un proceso global de transformación sociopolítica. El empeño, en lo que tiene de innovador, presenta sus atractivos a la vez que ciertamente comporta mayores dificultades para llevarle a buen término.

De antemano, pues, quiero dejar constancia de la renuncia obligada a la exhaustividad que tal propósito inicialmente me plantea. A cambio de ésta, que sin duda es la cualidad más apreciada en los repertorios bibliográficos de orden temático, en éste se ha intentado conseguir, tanto en la ordenación de sus epígrafes como en la selección de las obras recogidas, una muestra representativa mediante la cual se pudiera seguir la dinámica misma del proceso constituyente español.

A tal efecto, dicho repertorio, en su primer apartado, trata de enlazar, bibliográficamente, la crisis del régimen precedente con el actual. Crisis de la que se da cuenta a su vez mediante tres subepígrafes. En el primero de ellos, el de los antecedentes, son destacadas las interpretaciones más significativas que concibieron una salida para el régimen franquista cuando éste todavía era una realidad. Desde el Movimiento, la tecnocracia y lo que se ha conocido como la oposición democrática, se desarrollan a finales de los sesenta y en la década de los setenta una serie de planteamientos que tendían a prever la salida del régimen. De todos ellos se da aquí cuenta, si no en su totalidad, sí, a mi juicio, representativamente. He aquí el aspecto en el que lo novedoso del planteamiento se ve supeditado a la parcialidad de quien lo acomete. En un segundo subepígrafe se intenta poner de manifiesto las crisis parciales que el propio régimen guardaba en sus entrañas antes de su sustitución definitiva. Así, las crisis institucionales, las que van resquebrajando los apoyos sociales, económicos y políticos con que inicialmente contara, tienen en los títulos seleccionados una muestra que pretende ser lo suficientemente fidedigna de las progresivas y parciales insuficiencias que el franquismo fue acumulando a lo largo de su historia. La desproporción que a veces se obser- 
va en la referenciación de estas crisis parciales coincide con el interés, también desproporcionado, que el tratamiento de las mismas ha tenido.

Finalmente, dentro también de este primer apartado, se han querido recoger todas aquellas teorías más significativas que, ya en el ocaso del régimen, se ocuparon en dar cuenta de su necesaria desaparición. A veces me ha parecido oportuno reforzar éstas con ciertas obras en las que se han recogido las bases documentales de dicho régimen. Bases que a la postre no dejan de ser sino los resultados en unos casos de orden jurídico y en otros de carácter socioeconómico sobre las que aquellas interpretaciones se han levantado.

En un segundo apartado de este repertorio se han agrupado (quizá todavía hoy sea prematura su mayor sitematización) aquellos trabajos que bien en forma de crónica, bien como primeros ensayos interpretativos, han dado fe de la transición, o lo que es lo mismo, del momento en el que se iniciaba la sustitución del franquismo por una nueva realidad jurídico-política. Bases documentales, aspiraciones y temores acerca de lo que la reforma política sugería a sus autores han sido reunidos en este gran apartado. Con él se cierra esta primera parte del repertorio, que será completado con una segunda; en ella se intentará reflejar lo que esta dinámica ha comportado en el terreno socioeconómico, así como la articulación política que la misma ha dado lugar hasta la fecha. Igualmente recogerá las referencias bibliográficas a los líderes que han personalizado estas transformaciones; al contexto internacional y las implicaciones que éste ha podido tener en el proceso constituyente, así como, finalmente, a la dinámica mediante la que, todavía hoy, nos hallamos empeñados en una innovadora articulación territorial del Estado como un Estado autonómico.

\section{LA CRISIS DEL FRANQUISMO Y EL PROCESO CONSTITUYENTE}

\section{A) Antecedentes}

Anónimos y colectivos: Tácito, Ibérico Europea de Ediciones, Madrid, 1975.

ARIAS SAIGADO, R.: «Polémica sobre la interpretación de lạ Leyes Fundamentales: dimensión política y dimensión técnico-jurídica», en Sistema, núm. 5, abril 1974, págs. 93-101.

EstęBAN, J. de: «Desarrollo político y régimen constitucional español», en Sistema, núm. '2, mayo de 1973, págs. 67-76.

Esteban, J. de, y otros: Desarrollo político y Constitución española, Ariel, Barcelona, 1973.

Ferrando Badía, J.: Teoría de la instauración monárquica en España, Instituto de Estudios Políticos, Madrid, 1975.

Fraga Iribarne, M.: El desarrollo político, Grijalbo, Barcelona, 1972.

Fraga Iribarne, M. (ed.): La España de los años setenta, Moneda y Crédito, Madrid, 1974.

García SAN Miguel, L.: «Estructura y cambio del régimen político español», en Sistema, núm. 1, 1973, págs. 81-106.

- «Para una sociología del cambio político y la oposición en la España actual», en Sistema, núm. 4, enero 1974, págs. 89-108.

Herrero Rodríguez de Miñón, M.: El principio monárquico, Edicusa, Madrid, 1972.

- «La revisión de las Leyes Fundamentales», en Revista General de Legislación y Jurisprudencia, núm. 3, tomo LXX, marzo de 1975. 
Iglestas Selgas, C.: La vía española a la democracia, Ediciones del Movimiento, Madrid, 1968.

López Rodó, L.: Política y desarrollo, Aguilar, Madrid, 1971.

Ollero Gómez, C.: «Desarrollo político y Constitución española», en Boletín Informativo de Ciencia Política, núms. 13-14, 1973, págs. 5-27.

Solé Tura, J.: Introducción al régimen político español, Ariel, Barcelona, 1971. Tamames, R.: La República. La era de Franco, Alianza Universidad, Madrid, 1973.

\section{B) Las crisis parciales del franquismo}

Abellán, M. F.: «Sobre censura. Algunos aspectos marginales», en Cuadernos de Ruedo Ibérico, núms. 49-50, enero-abril 1974, págs. 125-139.

Aguiar de Luque, L.: Democracia directa y Estado constitucional, Edersa, Madrid, 1977.

Aguilar, M. A. (comp.): Los medios de comunicación en la frontera democrática, Universidad Internacional Menéndez y Pelayo, Madrid, 1982.

Alcalá, A.: «Le mouvement des enseignants», en Les Temps Modernes, número 357 , bis (monográfico dedicado a España), 1976, págs. 85-142.

Almendros Morcillo, F.: El sindicalismo de clase en España (1939-1977), Ediciones 62, Barcelona, 1978.

Alonso Tejada, L.: La represión sexual en la España de Franco, Círculo de Lectores, Barcelona, 1978.

Alonso, V. L.: Crisis agraria y luchas campesinas, 1970-76, Ayuso, Madrid,-1976.

Alvarez Bolado, A.: El experimento del nacionalcatolicismo, Edersa, Madrid, 1976.

Amsden, J.: Convenios colectivos y lucba de clases en España, Ruedo Ibérico, París, 1964.

Anaya Santos, G.: Una ruptura en la enseñanza, Fernando Torres, Editor, Valencia, 1977.

Anderson, CH. W.: The Political Economy of Modern'Spain, The University of Wisconsin Press, Wisconsin, 1970.

Anglada, M. L.: «Vint-i-cinc anys de moviments obrer a Catalunya», en Taula de Canvi, núm. 4, marzo-abril 1977, págs. 15-38.

Anónimos Y colectrivos: Iglesia y comunidad política, Universidad Pontificia de Salamanca, Salamanca, 1974.

- Anuario de las relaciones laborales en España, Ediciones de la Torre, Madrid, 1975.

- «La fiscalidad en el Estado español», en Cuadernos de Ruedo Ibérico, números 49-50, enero-abril 1974, págs. 78-110.

- La cultura bajo el franquismo, Enlace, Barcelona, 1977.

Aranguren, J. L., y otros: Dionisio Ridruejo, de la Falange a la oposición, Taurus, Madrid, 1976.

Areilza, J. M.: Figuras y pareceres, Ediciones del Espejo, Madrid, 1973.

- Cien artículos, Ediciones del Espejo, Madrid, 1973.

Artigues, D.: El Opus Dei en España. Su evolución ideológica y política, Ruedo Ibérico, París, 1971.

Baklanoff, E. M.: La transformación económica de España y Portugal. La economía del franquismo y el salazarismo, Espasa-Calpe, Madrid, 1980.

Barbancho, A. G.: Las migraciones interiores españolas en 1961-70, Instituto de Estudios Económicos, Madrid, 1975. 
Barbero, M.: «Postulados político-criminales del sistema punitivo español vigente: presupuestos para su reforma», en Sistema, núm. 10, julio 1975, págs. 99-113.

Barbero, M., y otros: La pena de muerte, seis respuestas, Universidad de Valladolid, 1975.

Barruquieta SÁez, A.: «La emigración española, el timo del desarrollo», en Cuadernos para el Diálogo (Suplemento), Madrid, 1976.

Benet, J.: Catalunya sota el regim franquiste, Blume, Barcelona, 1978.

BorJa, J.: «Crisis del Estado autoritario. Sistema de partidos en España», en Papers, núm. 8 (monográfico sobre el régimen franquista), Ediciones Península, Barcelona, 1978, págs. 143-172.

Broseta Pont, M.: «La integración de España en el Mercado Común: requisitos y obstáculos políticos y constitucionales», en Sistema, núm. 5, abril 1974, págs. 69-93.

Calvo SERer, R.: Franco frente al Rey, Ruedo Ibérico, París, 1972.

CAMPO, S. del: Crítica a la planificación social española (1964-1975), Castellote, Madrid, 1976.

Campo, S. del, M. Navarro y J. F. Tezanos: «Los españoles ante la cuestión regional», en Sistema, núm. 13, abril 1976, págs. 99-127.

Camuñas, I., y otros: España. Perspectiva 1974, Guadiana de Publicaciones, Madrid, 1974.

Canyelles, B., y Vidal, F.: L'oposiciò antifranquista a les illes, Gráficas Miramar, Palma de Mallorca, 1977.

Carballo, R.: Capitalismo y agricultura en España. La evolución de las relaciones de producción en el campo (1939-1975). Ediciones de la Torre, Madrid, 1977.

Carrillo, S., e IbÁrrurI, D.: Hacia la libertad (Informe del Comité Central presentado al VIII Congreso del PC de España), Ediciones Sociales, París, 1972.

Caudet, F.: Cultura y exilio. España peregrina, Fernando Torres, Editor, Valencia, 1976.

Celhay, P.: Consejos de guerra en España, Ruedo Ibérico, París, 1976.

Cisquella, G., y otros: Diez años de represión cultural. La censura de libros durante la Ley de Prensa (1966-1976), Anagrama, Barcelona, 1977.

Claudin, F.: «Le nouveau mouvement ouvrier espagnol», en Les Temps Modernes, núm. 357 bis (monográfico dedicado a España), 1976, págs. 9-56.

Colectivo 36: «Los límites de la censura histórica franquista», en Cuadernos Ruedo Ibérico, núms. 43-45, enero-junio 1975, págs. 139-149.

Conte Barrera, J.: Las asociaciones políticas, ATE, Barcelona, 1976.

Conte, R.: «Censure et auto-censure ou le nouvel art d'écrire», en Les Temps Modernes, núm. 357 bis (monográfico dedicado a España), 1976, págs. 350-384.

Connard Malerbe, E.: La oposición al franquismo, Naranco, Oviedo, 1977.

Cooper, N.: «La Iglesia: de la cruzada al cristianismo», en P. Preston, España en crisis. La evolución y decadencia del régimen de Franco, F. C. E., Madrid, 1978, págs. 93-146.

Cordero, F.: «Les appareils militaires en Espagne», en Les Temps Modernes, núm. 357 bis (monográfico dedicado a España), 1976, págs. 288-330.

Durr, E., y otros: Paro, inflación y crecimiento (La experiencia española, $1973-$ 1980), Espasa-Calpe, Madrid, 1980.

Equipo Cartelera Turia: Cine español, cine de subgéneros, Fernando Torres, Editor, Valencia, 1975.

EQUipo DE Estudios: Noticia, rumor y bulo: la muerte de Franco, Elías Querejeta, Madrid, 1976.

EsteBA, J. M.: «La política económica del franquismo: una interpretación», en 
P. Preston: España en crisis. La evolución y decadencia del régimen de Franco, F. C. E., Madrid, 1978, págs. 147-180.

Esteban, J. M.: Por una comunicación democrática, Fernando Torres, Editor, Valencia, 1976.

EtXezarReTa, A.: La economía española (1970-1979), Viejo Topo, Barcelona, 1979.

Fernández Alba, A.: Ideología y enseñanza de la Arquitectura en la España contemporánea, Tucar Ediciones, Madrid, 1975.

Figueruelo, A.: «L'éveil de la concience populaire en Espagne», en Les Temps Modernes, núm. 357 bis (monográfico dedicado a España), 1976, págs. 250-265.

Franco Salgado Araujo, F.: Mis conversaciones privadas con Franco, Planeta, Barcelona, 1976.

GalÁN, D.: Reírse en España. El bumor español en el banquillo, Fernando Torres, Editor, Valencia, 1974.

García Sanmiguel, L.: Escritos sobre la libertad política y el socialismo, Fernando Torres, Editor, Valencia, 1976.

García Valdés, C.: No a la pena de muerte, Edicusa, Madrid, 1975.

Grl Delgado, F.: Conflicto Iglesia-Estado (España 1808-1975), Sedmay, Barcelona, 1975 .

GINER, S.: «Spain», en M. S. Archer (ed.): Students University and Society, Heinemann Educational Books, Londres, 1972, págs. 103-126.

- «Libertad y poder en la Universidad española: el movimiento democrático bajo el franquismo», en P. Preston: España en crisis. La evolución y decadencia del régimen de Franco, F. C. E., Madrid, 1978, págs. 303-357.

Gómez PÉrez, R.: Politica y religión en el régimen de Franco, Dopesa, Barcelona, 1974.

GonzÁlez Anleo, J.: Catolicismo nacional: nostalgia y crisis, Ediciones Paulinas, Madrid, 1975.

GonzÁlez, M. J.: La economía política del franquismo (1940-1970). Dirigismo, mercado y planificación, Tecnos, Madrid, 1978.

GunTler, R.: Public policy in a no-party State (Spanish planing and bugetin in the twilight of the franquist era, University of California Press, Berkeley, 1980.

Hansen, E. C.: Rural catalonia under the Franco regime, Cambridge University Press, Cambridge, 1977.

Hermet, G.: Les Catboliques dans l'espagne franquiste, Presses de la Fondation de Sciences Politiques, París, 1981.

IвÁ்́̃EZ, P. A.: «Notas para una posible reforma democrática de la justicia», en Sistema, núms. 17-18, abril 1977, págs. 111-124.

Infante, J.: La prodigiosa aventura del Opus Dei. Génesis y desarrollo de la Santa Mafia, Ruedo Ibérico, París, 1970.

INFANTE y otros: «Le mouvement des travailleurs de la santé», en Les Temps Modernes, núm. 357 bis (monográfico dedicado a España), 1976, págs. 224-249.

Jones, N.: «El problema catalán desde la guerra civil», en P. Preston, España en crisis. Evolución y decadencia del régimen de Franco, F. C. E., Madrid, 1978, págs. 389-444.

Kindelán, A.: La verdad de mis relaciones con Franco, Planeta, Barcelona, 1981.

LACALle, D.: El conflicto laboral en profesionales y técnicos, Editorial Ayuso, Madrid.

Laín Entralgo, P.: Descargo de conciencia, Barral Editores, Barcelona, 1974.

LARA, F., y otros: Siete trabajos de base sobre el cine español, Fernando Torres, Valencia, 1975. 
LeTAMENDía, F.: Historia de Euskadi: el nacionalismo vasco y ETA, Ruedo Ibérico, París, 1975.

Linde Paniagua, E.: Amnistía e indulto en España, Tucar Ediciones, Madrid, 1976.

López Pina, A., y Aranguren, E. L.: La cultura política de la España de Franco, Taurus, Madrid, 1976.

López Pintor y R. Buceta: Los españoles de los años setenta, Tecnos, Madrid, 1975.

LUdEvID, M.: El movimiento obrero bajo el franquismo, Avance, Barcelona, 1977.

LLEWELYN, J.: «Separatismo revolucionario vasco: ETA», en P. PRESTON, España en crisis. Evolución y decadencia del régimen de Franco, F.C. E., Madrid, 1978 , págs. 389-444.

Malerbe, P. C.: La oposición al franquismo, 1939-1975, Naranco, Madrid, 1977.

Maravall, J. M.a. Dictadura y disentimiento político. Obreros y estudiantes bajo el franquismo, Alfaguara, Madrid, 1978.

Marcos Alonso, J.: Los ingenieros entre el pasado y el futuro, Laia, Barcelona, 1975.

Martín, E., y SALvador, J.: Las elecciones sindicales, Laia, Barcelona, 1975.

Martín Martínez, I.: Revisión del concordato de 1953 en la perspectiva del episodio español, Fundación Universitaria, Madrid, 1974.

Martínez de Bedoya, J.: El desafío de la libertad, Unión Editorial, Madrid, 1974.

MARTÍNEz EstÉvez, A.: Reflexiones en torno a la crisis económica de los años setenta, Fernando Torres, Valencia, 1977.

Martínez Reverte, J.: «Le chemin difficile de la liberté», en Les Temps Modernes, núm. 357 bis (monográfico dedicado a España), 1976, págs. 394-419.

Martínez Val, J. M.: ¿Por qué no fue posible la Falange?, Dopesa, Barcelona, 1975.

Marzal, A.: «La empresa española como problema», en Sistema, núm. 20, septiembre 1977, págs. 67-77.

Mendhurst, N. K.: Government in Spain, Pergamion Press, Oxford, 1973.

Mellont, A., y ZaGolin, M. S.: «L'informationi durante il franchismo fra la lege e l'infrazioni», en Il Politico, diciembre 1981, año XLVI, núm. 4.

Mrguel, A. de: Desde la España predemocrática, Ediciones Paulinas, Madrid, 1976.

- «Actitudes políticas españolas, 1970», en S. G. PAyne, Política y sociedad en la España del siglo XX, Akal, Madrid, 1978.

- Franco, Franco, Franco, Ediciones 99, Madrid, 1976.

Miret Magdalena, E.: Catolicismo para mañana, Desclee de Brouwer, Bilbao, 1974. Por una nueva educación religioso-moral, Adara Educación, La Coruña, 1976.

Moya, C.: El poder económico en España (1939-1970), Tucar Ediciones, Madrid, 1975.

Muro DE Iscar, F.: La universidad de las puertas cerradas, Ediciones Paulinas, Madrid, 1975.

Navarro Rubro, M.: El vacio político, Madrid, 1973.

Olarra Jiménez, J.: Medidas de política monetaria adoptadas en el período 1957-1976, Banco de España, Madrid, 1976.

Oliver, J., y otros: La prensa clandestina. Propaganda y documentos antifranquistas, Planeta, Barcelona, 1978.

Oltra, B., y DE Miguel, A.: «Bonapartismo y catolicismo. Una hipótesis sobre los orígenes ideológicos del franquismo", en Papers, núm. 8 (monográfico dedicado al franquismo), 1976, págs. 264-288. 
Paramio, L.: «Le bloc dominant dans L'Espagne de Franco», en Les Temps Modernes, núm. 357 bis (monográfico dedicado a España), 1976, págs. 264-288.

PARís, C.: La universidad española actual: posibilidades y frustraciones, Edicusa, Madrid, 1974.

Peces-Barba, G., y otros: Libertad de expresión, reunión y asociación, Fernando Torres, Editor, Valencia, 1976.

Pérez Díaz, V.: Cambio tecnológico y procesos educativos en España, Seminario y Ediciones, Madrid.

Peris, M.: Juez, Estado y derechos bumanos, Fernando Torres, Editor, Valencia, 1976.

Petschen, S.: La Iglesia en la España de Franco, Sedmay, Madrid, 1977.

PICo LóPEZ, J.: El moviment obrer al País Valenciá sota el franquisme, Climent, Valencia.

Ramírez, J. A.: El comic temenino en España, Edicusa, Madrid, 1975.

Rego ChaO, J.: La Iglesia en el franquismo, Felmar, Madrid, 1976.

RIERA, I.: «Moviment obrer i gestió nacional sota el franquisme», en Taula di Canvi, núm. 4, marzo-abril 1977, págs. 5-15.

Ros Hombravela, J.: Politica económica española (1959-1973), Blume, Barcelona, 1973.

RuIz RIco, J. J.: El papel político de la Iglesia católica en la España de Franco, Tecnos, Madrid, 1977.

Sáez AlbA, A.: «La otra cosa nostra». La Asociación Católica Nacional de Propagandistas, Ruedo Ibérico, París, 1973.

SÁNCHEZ; E.: Camina o revienta. Memorias de «El Lute», Edicusa, Madrid, 1977.

SARTORIUS, N.: El resurgir del movimiento obrero, Laia, Barcelona, 1975.

SCHWARTZ, P., y GonZÁLEZ, M. J.: Una bistoria del Instituto Nacional de Industria (1941-1976), Tecnos, Madrid, 1978.

SETIÉN, J.: El movimiento obrero y el sindicalismo de clase en España (19391981), Ediciones de la Torre, Madrid, 1982.

Sevilla, E.: El campesinado en el desarrollo capitalista español.

STEVENS, E. P.: «Protest movement in an authoritariam regime», en Comparative Politics, 7 (3), 1975, págs. 361-382.

Tamames, R.: La oligarquia financiera en España, Planeta, Barcelona, 1977.

Terrón Moreno, J.: La prensa en España durante el régimen de Franco, Centro de Investigaciones Sociológicas, Madrid, 1981.

TEZANos, J. F.: La estructura de clases en la España actual, Edicusa, Madrid, 1975.

Toharia, J. J.: «Judicial independencia in an authoritarian regime: The case of contemporary Spain», en Law Social Review, 9 (3), 1975, págs. 475-496.

- Cambio social y vida jurídica en España, Edicusa, Madrid, 1974.

Treves, R.: El juez y la sociedad, Edicusa, Madrid, 1974.

Tussell, J., La oposición democrática al franquismo, Planeta, Barcelona, 1977.

VázQuez Montalvan, M.: Los demonios familiares de Franco, Dopesa, Barcelona, 1978.

VEGA, E.: «Un ejemplo de reestructuración antipopular: las Cajas de Ahorro», en Cuadernos de Ruedo Ibérico, núms. 61-62, enero-abril 1979, págs. 66-74.

VILAR, S.: La oposición a la dictadura, Ayma, Barcelona, 1976.

- Carta abierta a la oposición, Planeta, Barcelona, 1977.

Zaragoza, A.: Abogacia y política, Edicusa, Madrid, 1975.

Zorrilla Castresana, R.: Sociología de las manifestaciones, Desclee de Brouwer, Bilbao, 1976. 


\section{C) La crisis del régimen franquista: interpretaciones}

Acosta SÁNChez, J.: Crisis del franquismo y crisis del imperialismo, Anagrama, Barcelona, 1976.

Alba, J.: Todos somos berederos de Franco, Planeta, Barcelona, 1980.

Amodia, J.: Franco's political legacy: from dictatorsbip to facade democracy, Alone, Londres, 1977.

Beck, R.: «Die Ataats-und verfassungrchtliche Entwiclung in Spanien 1972 1977», en Jabrburch des Öffentlichen Rechts der Gegenwart, núm. 26, 1977, págs. 279-314.

BeN AMI, Sh.: La revolución desde arriba: España 1936-1979, Riopiedras, Ediciones, Barcelona, 1980.

Biescas, J. A., y TuÑón de LARA, M.: España bajo la dictadura franquista (1939. 1975), Labor, Barcelona, 1980.

Carr, R,, y Fusr, J. P.: De la dictadura a la democracia, Planeta, Barcelona, 1979.

Cierva, R. de la: La bistoria se confiesa. España 1930-1977, tomo XI, Planeta, Barcelona, 1978.

- Historia del franquismo: aislamiento, transformación, agonía (1945-1975), Planeta, Barcelona, 1978.

Coverdale, J. F.: «Spain from dictatorship to democracy», en International Affairs, octubre 1977, págs. 615-630.

Crozier, B.: Franco, crepúsculo de un bombre, Planeta, Barcelona, 1980.

Díaz-Plaja, F.: La España franquista en sus documentos, Madrid, 1976.

Equipo Democracia 2000: El adiós a la democracia orgánica, Pecosa, Madrid, 1976.

Esteban, J. de, y López Guerra, L.: La crisis del Estado franquista, Labor, Barcelona, 1977.

Ferrando Badía, J.: «De la monarquía del 18 de julio a la monarquía parlamentaria del proyecto constitucional de 1978», en J. Carprzo (coordinador), Las experiencias del proceso político-constitucional en México y España, Universidad Autónoma de México, 1979, págs. 15-97.

GaRCía Fernández, J.: El régimen de Franco. Un análisis político, Akal, Madrid, 1976.

García Nreto, M. C., y otros: La España de Franco. Bases documentales de la España contemporánea, Guadiana de Publicaciones, Madrid, 1975.

GonZÁlez Doria, F.: ¿Franquismo sin Franco?, Cunillera, Madrid, 1974.

Herms, I., y Kopinger, P.: Von der Diktatur zur Demokratie, dans Beispiel - Spaniens und Portugals, Dunker und Humblot, Berlín, 1976.

Hermet, G.: L'Espagne de Franco, Armand Colin, París, 1974.

- «La España de Franco: formas cambiantes de una situación autocrática», en Manuel Tuñón dE LARA, Ideología y sociedad en la España contemporánea, Edicusa, Madrid, 1977.

Herzog, W.: Spanien: der Fascbismus, die demokratische Oposition un die revolutionare, Kusbuch, dec, 1976.

HöHN, W.: Spanien 1936-1976: Kampf für Freibeit und Demokratie, RödarbergVerlag, Francfort, 1976.

JACKSON, G.: «L'epoca di Franci in prospectiva histórica», en Revista Stórica Italiana, núm. 2,'1976, págs. 283-306.

Jiménez CAMPo, J.: «Crisis política y transición al pluralismo en España (19751978)», en A. Predieri y E. G. DE ENTERría, La Constitución española de 1978, Civitas, Madrid, 1980, págs. 19-41. 
Leoni, F.: La Spagna dopo Franco, Cappelli, Bolonia, 1974.

Linz, J. J.: «An authoritariam Regime: Spain», en Erik AlladT y Stein Rokkan, Mas polities. Studies in political sociology, The Free Press, Nueva York, 1970, págs. 374-381. Hay traducción al castellano en Manuel Fraga Iribarne y otros, La España de los años setenta, tomo I, Moneda y Crédito, Madrid, 1974, páginas 1467-1530; también en Stanley G. PAYNe, Política y sociedad en la España del siglo XX, Akal, Madrid, 1978, págs. 205-267.

MaIER, L. P.: «Spanien. Agonie der Diktatur», en Blätter fur deutsche und internationale politik, noviembre 1974, págs. 1178-1190.

Marías, J.: La España real, Espasa-Calpe, Madrid, 1977.

- España en nuestras manos, Espasa-Calpe, Madrid, 1978.

- La devolución de España, Espasa-Calpe, Madrid, 1978.

Martín Oviedo, J. M.: «De la ley fundamental del reino a la nueva ordenación constitucional española», en Revista de Derecbo Público, núms. 68-69, 1978, págs. 643-666.

Miguel, A. de: Sociología del franquismo, Editorial Euros, Barcelona, 1975.

- La berencia del franquismo, Cambio 16, Madrid, 1976.

Muro DE IsCAR, F., y CASTELo, S.: España, su inmediato futuro político, Ediciones Acervo, Barcelona, 1975.

Oronoz, J.: Transformaciones del sistema capitalista y evolución de la formación social española (1939-1979), Editorial Lul, San Sebastián, 1980.

Poulantzas, N.: La crisis de las dictaduras: Portugal, Grecia y España, Siglo XXI, Madrid, 1976.

Preston, P.: Spain in crisis: The evolution and decline of the Franco regime, Hassocks (Sussex), Havester, 1976. Hay traducción al castellano: España en crisis: la evolución y decadencia del régimen de Franco, F. C. E., Madrid, 1978.

Ramírez, M.: España 1939-1975. Régimen político e ideología, Guadarrama, Barcelona, 1978.

RoA, V.: Apoteosis y ocaso del franquismo, Sedmay, Madrid, 1976.

RoA Ventura, A.: Agonía y muerte del franquismo, Barral, Barcelona, 1978.

RoNY, J.: La lente rupture: l'Espagne du franquisme a la démocratie, Editions Socials, 1977.

Sevilia, E., y Giner, S.: «Absolutismo despótico y dominación de clase. El caso de España», en Cuadernos de Ruedo Ibérico, núms. 43-45, enero-junio 1975, págs. 83-104.

Sevilia, E., y otros: «Despotismo moderno y dominación de clase: para una sociología del régimen franquista», en Papers, núm. 8 (monográfico sobre el régimen franquista), Ediciones Península, Barcelona, 1978, págs, 103-143.

Tamames, R.: Un proyecto de democracia para el futuro de España, Edicusa, Madrid, 1975.

Termine, E., y otros: Histoire de l'Espagne contemporaine, Aubier Montaigne, París, 1979. Hay traducción al castellano en Ariel, Barcelona, 1982.

Vidal Beneyto, J.: Del franquismo a una democracia de clase, Akal, Madrid, 1977.

VIllar, S.: La naturaleza del franquismo, Ediciones Península, Barcelona, 1977.

- «Die Olinmacht der Diktatur und die Nacht der Demokratie. Zur politischen lage in Spanien nach der Parlaments Wahlen», en Blätter für Deutscbe und Internationals Politik, julio 1977, págs. 731-841.

Willms, J.: «Das franquistilche System un die Spanische Wirtschaft», en Lus Politik und Zeitgeschichte, 14 (9), 1977, págs. 35-46. 


\section{CRONICAS E INTERPRETACIONES DE LA TRANSICION}

Agurrre, J. A.: La política económica de la transición española 1975-1980, Unión Editorial, Madrid, 1981.

AlCALÁ, M.: «L'Espagne en Mouvement», en Études, agosto-septiembre, 1976, págs. 146-163.

Alvarez de Miranda, F.: Al servicio de la democracia, Diario Día, Palencia, 1979. Alzaga, O.: «El actual proceso constituyente español», en Revista de Derecho Público, núms. 68-69, 1977, págs. 667-680.

- La Constitución española de 1978 (comentario sistemático), Ediciones del Foto, Madrid, 1979.

- «Reflexiones sobre una crisis grave», en Revista de Derecbo Político, Universidad Nacional de Educación a Distancia, núm. 10, verano 1981, págs. 133-144.

Amalric, J. P.: «Métamorphose de l'Espagne», en Études, enero 1978, págs. 7-25.

ANÓNIMAS Y COLECTIVAS:

- «España quiere democracia», en Cuadernos para el Diálogo, diciembre 1975, págs. 14-33.

- Calendario de la reforma política, Presidencia del Gobierno, Madrid, 1976.

- La crisis, la reforma y los trabajadores, Ediciones de la Torre, Madrid, 1976.

- Proyecto de ley para la reforma política, Secretaría General Técnica de la Presidencia del Gobierno, Madrid, 1976.

- Libro blanco para la reforma democrática, Godsa, Madrid, 1976.

- Comentarios políticos de actualidad, Unión, Madrid, 1976.

- Primer año de posfranquismo, Madrid, 1976.

- «Reforma o ruptura», en Cuadernos para el Diálogo, enero 1976, págs. 7-19.

- «Momento actual español», en Razón y Fe, mayo 1976, págs. 387-474.

- Cómo se construye la democracia, Avance, Madrid 1977.

- El proceso bistórico de la reforma política española, Documentación Española, Madrid, 1977.

- «Etica de la transición política», en Revista de Fomento Social, abril-junio 1977, págs. 113-154; incluye también un apéndice documental sobre orientaciones políticas de los obispos españoles en las págs. 189-214.

- Democracia para España, 2 vols., Unión Editorial, Madrid, 1977.

- Documentos para un cambio político, PPC, Madrid, 1978.

- Transición a la democracia en el sur de Europa y América Latina, Centro de Investigaciones Sociológicas, Madrid, 1981.

Arbeola, V.: ¿Una constitución democrática?, Mañana Editorial, Madrid, 1977.

Areilza, J. M.: Diario de un ministro de la monarquía, Planeta, Barcelona, 1977.

Aresti, J.: España, situación actual, Espasa-Calpe, Madrid, 1977.

Arias Navarro, C.: Calendario para la reforma política, Secretaría General Técnica de la Presidencia del Gobierno, Madrid, 1976.

Asís, A. DE: Escritos ante una reforma constitucional, Madrid, 1975.

Baena, M., y García MadaIra, J. M.: Normas políticas y administrativas de la transición 1975-1978, Presidencia del Gobierno, Madrid, 1982.

BaIlloy, E.: España bacia la democracia, Argós-Vergara, Barcelona, 1977.

BELFIORE: «La Espagna tra riforme e rottura», en Allari Eteri, núm. 31, 1976, págs. 451-461.

Blanco Tosío, M.: Blues para una democracia, Doncel, Madrid, 1977.

Borbón PARMa, M. T.: El momento actual español cargado de utopía, Cuadernos para el Diálogo, Madrid, 1977. 
Bosch-Gimpera, P.: La España de todos, Seminarios y Ediciones, Madrid, 1976. Bourricaud, F.: «L'Espagne a la recherche du régime qui divise le moins», en Contrepoint, núm. 21, 1976, págs. 9-20.

Calvo SERER, R.: Eurocomunismo, presidencialismo y cristianismo, Unión Editorial, Madrid, 1982.

Camacho, I., y Caston, P.: «Les 100 jours de la democratie espagnole», en Proyet, noviembre 1977, págs. 1115-1122.

CAMpos Ríos, G.: «EI poder político y la Constitución», en Ruedo Ibérico, números 61-62, enero-abril 1979, págs. 13-26.

Canals Vidal, F.: Política española: pasado y futuro, Acervo, Barcelona, 1977.

Carcassonne, G., y Subra de Bieusses, P.: L'Espagne ou la democratie retournée, Enaj, París, 1978.

Carrillo, S.: Hacia el posfranquismo: comunicado de la reunión del pleno ampliado del Comité Central del PC de España, Librairie du Globe, París, 1975.

- ¿Qué es la ruptura democrática?, La Gaya Ciencia, Barcelona, 1976.

- «Spain, today and tomorrow», en Societat Revolution, julio-agosto 1977, páginas 37-63.

- El año de la Constitución, Grijalbo, Barcelona, 1978.

Cataldi, L.: Spagna, il patto della libertà, Marsilio, Venecia, 1975.

Cebrián, J. L.: La España que bosteza. Apuntes para una bistoria crítica de la transición, Taurus, Madrid, 1980.

Cela, C. J.: El reto de los balcones: antología de la prensa apocalíptica española en la apertura, Júcar, Madrid, 1975.

Cierva, R. de la: La cuarta apertura, Ediciones Paulinas, Madrid, 1976.

- Crónicas de la confusión, Planeta, Barcelona, 1977.

Cirici Pellicer, A.: Murals per la llibertat, Abadía de Montserrat, 1977.

Colomer, J.: «Punto de partida», en Razón y Fe, julio-agosto 1977, págs. 728-738.

- «Constitución: el itinerario de un texto», en Razón y Fe, julio-agosto 1978, págs. 50-64.

Coser, L.: «Spain on the eve», en Dissent, 23 (4), Nueva York, 1976, páginas 338-348.

Chambre Mariño, J.: «La herencia del franquismo», en Cuadernos Americanos, $35(2), 1976$.

Chao, R.: Después de Franco, España, Felmar, Madrid, 1976.

Debray, R., y Gallo, M.: Demain l'Espagne, Seuil, París, 1974. Hay versión en castellano en Akal, Madrid, 1976.

Eguilaz, H.: Una política para España, Madrid, 1976.

Equipo Democracia 2000: Primer año del posfranquismo, Pecosa Editorial, Madrid, 1977.

Equipo de Estudios: Al filo de la crisis, Felmar, Madrid, 1975.

Esperabé ARTEAGA, J.: En torno a nuestras instituciones, Sedmay, Madrid, 1976.

Esteban, J. de: «Las bases de una Constitución para España», en Sistema, número 19, julio 1977, págs. 103-119.

Esteban, J. de, y López GuerRa, L.: De la dictadura a la democracia, Facultad de Derecho, Madrid, 1979.

Fernández DE CAstro, I.: Prueba de fuerza entre el reformismo y la ruptura, Ed. Querejeta, Madrid, 1976.

Fernández ORdóñez, F.: La España necesaria, Taurus, Madrid, 1980.

- Palabras en libertad, Argos-Vergara, Madrid, 1982.

Figueredo, J.; Baselga, A., y Madariaga, C. G.: Las reformas urgentes, Taller de Ediciones J. Betancor, Madrid, 1976.

Fraga IrIbarne, M.: Un objetivo nacional, Dirosa, Barcelona, 1975. 
Fraga Iribarne, M.: España en la encrucijada, Adra, Madrid, 1976.

- Los nuevos diálogos, Planeta, Barcelona, 1977.

- La Constitución y otras cuestiones fundamentales, Planeta, Barcelona, 1978.

- Después de la Constitución y bacia los años ochenta, Planeta, Barcelona, 1979.

- Memoria breve de una vida pública, Planeta, Barcelona, 1979.

Fraser, R.: «Spain on the brink», en New Left Review, marzo-abril 1976, páginas 3-33.

Gambra CIUdAd, R.: Tradición o mimetismo: la encrucijada política del presente, IEP, Madrid, 1976.

Garcia de Madariaga, J. A.: Discursos por una sociedad democrática, Madrid, 1978.

García PÉrez, J.: «La Spagna ha scelto la democrazia», en Civiltd̀ Cattolica, número 128, 1977, págs. 185-194.

García San Mrguel, L.: Teoría de la transición, Editora Nacional, Madrid, 1981.

García Trevijano, A.: La alternativa democrática, Plaza y Janés, Madrid, 1977.

Garrigues, J.: Una política para España, Unión Editorial, Madrid, 1976.

- Un año antes, un año después, Unión Editorial, Madrid, 1978.

- Un nuevo modelo de Estado, Unión Editorial, Madrid, 1980.

Gil-Robles y QuiÑones, J. M.: Marginalia política, Ariel, Barcelona, 1975.

- Esquema de un camino bacia la democracia, Equipo Demócrata-Cristiano, Madrid, 1976.

Girón de Velasco, J. A.: Reflexiones sobre España, Planeta, Barcelona, 1975.

Gómez Camacho, F.: «Cambio político y reforma económica en la actual coyuntura española», en Revista Fomento Social, núm. 31 (121), 1976, págs. 7-12.

González Casanova, J. A.: La lucba por la democracia en España, Avance, Barcelona, 1975.

GonzÁlez Doria, F.: ¡Franquismo sin Franco!, Cunillera, Madrid, 1974.

GonzÁlez Navarro, F.: La nueva ley fundamental para la reforma política, Presidencia del Gobierno, Madrid, 1977.

González Seara, L.: España en el umbral del cambio, Información y Publicaciones, Madrid, 1975.

Granados, J. L.: 1975, el año de la instauración, Ediciones Giner, Madrid, 1977.

GRupo Tácito: Tácito, Ibérico Europea, Madrid, 1975.

Guillamón, V. A.: La política al desnudo: con un epílogo sobre el futuro de España, Guillamón, Alboraya, 1975.

Haro Tecglen, E., y otros: «Balance de cinco años: el posfranquismo», en Tiempo de Historia, año VI, núm. 72 (especial).

HaRri, P.: «Crónicas del tránsito hacia la nada», en Cuadernos de Ruedo Ibérico, núms. 51-53, mayo-octubre de 1976, págs. 51-90.

Heras, J. de las: El último año de Franco: diario político español, 1975, Sedmay, Madrid, 1976.

HeRMET, G.: «L'Espagne en 1975: evolution ou rupture?», en Defense Nationale, agosto-septiembre 1975, págs. 43-58.

- «L'Espagne en 1976: les chances de la démocratie octroyée», en Defense Nationale, enero 1977, págs. 75-83.

- «Espagne: changement de la société, modernisation autoritaire et démocratie otroyée», en Revue Française Science Politique, núm. 27 (4-5), 1977, páginas $582-600$.

- «Espagne, lendenmain d'election», en Defense Nationale, 1977, págs. 45-58.

Hernando, A., y Martínez Alier, J.: «La reforma política, el ejército y la representación orgánica del capital», en Cuadernos de Ruedo Ibérico, núms. 6162 , enero-abril 1979 , págs. 27-46. 
Herrera Oria, A.: Meditación sobre España, B. A. C., Madrid, 1976.

Herrero Lera, M.: El proceso constituyente español: de la Ley 1/1977, de 4 de enero, para la reforma política a la Constitución española de 30 de diciembre de 1978, UNED, Madrid, 1979.

- «Proceso constituyente y sistema de partidos», en Cuadernos de Derecbo Constitucional, Universidad Internacional Menéndez y Pelayo, Madrid, 1981, páginas $445-474$.

Herrero Rodríguez de MiÑón, M.: «Falsas y verdaderas vías del consenso constitucional», en $R E P$, núm. 9, 1979, págs. 73-99.

Hernández Gil, A.: El cambio político español y la Constitución, Planeta, Barcelona, 1982.

Hijas Palacios, A.: Ante el futuro democráticos su proyección planetaria, continental y nacional, Studium, Barcelona, 1976.

Hillers DE LuQue, S.: España, una revolución pendiente, Fondo de Estudios Sociales, Madrid, 1975.

HotTinger, A.: Spain in transition, Beverly Hills (Calif.), Sage Publications, 1974.

- «Spanien ein jahr nach Franco», en Europe Arcbiv, núm. 31 (22), 1976, págs. 697706. También en inglés en World Today, núm. 31 (12), 1976, págs. 441-450.

- «Die politischen Kräfte Spaniens heute-Übersicht und Bewertung», en Butrege zur Kanflikfourcbung, núm. 1, 1976, págs. 63-76.

- «Spain on the road to democracy», en The World Today, septiembre 1977, págs. 353-362.

- «Spanien auf dum Weg zur Demokratie», en Europe Arcbiv, núm. 32 (16), 1977, págs. 515-524.

Iglesias Selgas, C.: Una alternativa democrática, Instituto de Estudios Sindicales, Madrid, 1977.

Izquierdo, A.: El año siguiente, Acervo Ediciones, Barcelona, 1977.

IzQuierdo, M. P.: De la buelga general a las elecciones generales, De la Torre, Madrid, 1977.

JimÉnez Blanco, J.: De Franco a las Elecciones Generales, Tecnos, Madrid, 1978.

Kolm, S. C.: «¿Puede ser el programa común al principio de la transición?», en Zona Abierta, núm. 13, 1977, págs. 42-62.

Lasuen, J. R.: La España mediocrática, Planeta, Barcelona, 1979.

LiNz, J. J.: Spain an Portugal: Critical Choices, en D. S. Landes Ed.

- Western Europe: The trials of partnership, Lexington (Mass.), D. C. Heath Co., 1977, págs. 237-296.

- The inauguration of democracy government and its prospects in Spain (multicopiado).

LINZ, J. J., y otros: Informe sociológico sobre el cambio político en España (19751981), Euroamérica, Madrid, 1981.

LuCAs Verdú, P.: La octava ley fundamental: crítica jurídico-política de la reforma Suárez, Tecnos, Madrid, 1976.

- «La singularidad del proceso constituyente español», en $R E P$, núm. 1, 1978, págs. 9-28.

MaIER, L. P.: Spaniens Weg zur Demokratie, Anton Hain, Meisenheim am Glau, 1977.

MaOrtua, A.: España boy, Fuerza Nueva, Madrid, 1975.

Maravall, J. M.a: La política de la transición, 1975-1980, Taurus Ediciones, Madrid, 1982.

Marías, J.: Cinco años de España, Espasa-Calpe, Madrid, 1982.

Márquez Reviriego, V.: Apuntes parlamentarios. La tentación canovista, Editorial Saltes, Madrid, 1978. 
Martín-Retortillo, L.: En los albores de la democracia, Buara Editorial, Zaragoza, 1979.

MarTín VILLA, R.: «Análisis sociológico de la transición política», en Revista de Política Comparada, núm. 4, primavera 1981, págs. 21-37.

Martínez Alier, J.: «Contra la reconciliación», en Cuadernos de Ruedo Ibérico, núms. 43-45, enero-junio 1975, págs. 27-81.

MeILÁN GIL, J. L.: Escritos sobre la trasición política española, Ediciones Mayler, Barcelona, 1979.

MeISLER, S.: «Spain's new democracy», en Foreing Affairs, 56 (1), 1977, páginas 190-208.

MeLIÁ, J.: ¿Qué es la reforma política?, La Gaya Ciencia, Barcelona, 1976.

- El largo camino de la apertura, Dopesa, Barcelona, 1975.

MerTens, M. J.: «Spanien heute», en Deutsche Aussen Politik, marzo 1976, páginas 264-274.

Miguel, A. de: Cuarenta millones de españoles cuarenta años después, Grijalbo, Barcelona, 1976.

Miret Magdalena, E.: España, destino socialismo, Sedmay, Madrid, 1976.

Moreno, I.: Apostando a la democracia, Akal, Madrid, 1975.

MORILlas GómEZ, J.: Una brecha para la revolución en España, Departamento de Prensa de Falange Auténtica, Madrid, 1978.

MORODO, R.: «Proceso constituyente y nueva Constitución española: anotaciones al preámbulo constitucional», en Boletín Informativo del Departamento de Derecbo Político, núm. 1, UNED, 1978, págs. 5-18.

Muro de IsCAR, F.: España, su inmediato futuro político, Acervo, Barcelona, 1975.

NAvArro GonzÁlez, F.: La apertura y la apretura, Mirasierra, Madrid, 1975.

Olarra Ugarte, L.: Posfranquismo: proyecto de futuro, Deusto, DL, Bilbao, 1977.

OnETo, J.: Arias entre dos crisis, Cambio 16, Madrid, 1975.

Osorio, A.: Trayectoria politica de un ministro de la Corona, Planeta, Barcelona, 1980.

Otto y PARdo, I. de: ¿Qué son la Constitución y el proceso constitucional?, La Gaya Ciencia, Barcelona, 1977.

Pallach, J.: Democracia, per fer qué, Nova Terra, Barcelona, 1975.

Papell Cervera, A.: España y el futuro, Dirosa, Barcelona, 1976.

PASEYRO, R.: «L'Espagne sur le fil», en Contrepoint, diciembre 1976, págs. 159166.

Pérez Sadava, V.: «Problemas políticos de la España actual», en Indice, Madrid, 1975.

PÉRez Tremps, P.: «La ley para la reforma política. Aspectos de la transición política española», en Revista de la Facultad de Derecho de la Universidad Complutense, núm. 54, 1978, págs. 125-177.

Pillado, R.: «De la defensa de la república a la aceptación de la monarquía instaurada», en Cuadernos de Ruedo Ibérico, núms. 51-53, 1976, págs. 50-91.

PIÑar, B.: Combate por España, Fuerza Nueva, Madrid, 1975.

Plagnet, B.: «Espagne: la necesité de la démocratie», en Revue Politique et Parlamentaire, núm. 869,1977 , págs. 69-83.

Pont Mestres, M.: Realismo Politico, Plaza y Janés, Barcelona, 1977.

Prat Ballester, J.: La democracia como objetivo, Hispano-Europea, Barcelona, 1978. 
Prieto, F.: «La Spagna verso la democracia», en Aggionamenti Sociali, núm. 28 (1), 1977, págs. 23-38.

- Anuario de la política española de 1977, CEC, Madrid, 1978.

Pujades, M.: «La clase obrera devant la transició política. Dues questions actual del sindicalisme de masses», en Taule de Canvi, núm. 4, marzo-abril 1977, págs. 45-53.

RAMA, C. M.: España, crónica entrañable, 1973-77, Grijalbo, Barcelona, 1979.

RIDDEL, F. S.: «The political dilemma of Spain», en India Quaterly, núm. 32 (2), 1976, págs. 189-206.

RidRuejo, D.: Casi unas memorias, Planeta, Barcelona, 1976.

Río Cisneros, A. del: Viraje político español, Madrid, 1977.

Rodríguez, C.: Continuidad o cambio: vigencia y perspectivas del Estado del 18 de julio, Doncel, Madrid, 1975.

Rodríguez Carlos, E.: La larga marcha hacia la libertad, Doncel, Madrid, 1977.

Romero, E.: Cartas pornopolíticas, Planeta, Barcelona, 1977.

- El discreto impertinente, Planeta, Barcelona, 1978.

Romero Maura, J.: «After Franco, Franquismo?: The Armed Forces the crown and Democracy», en G. E O., XI (1), 1976, págs. 35-64.

SAlmador, V.: Don Juan de Borbón. Grandeza y servidumbre del deber, Edilibro, Madrid, 1976.

SÁNCHEZ AgESTA, L.: «Momento constitucional: la reforma constitucional», en $R e$ vista de Derecbo Público, núm. 63, 1976, págs. 225-256.

- «La nueva ley fundamental para la reforma política», en Revista de Derecho Público, núm. 66, 1977, págs. 5-12.

Sempere Corral, P.: Los muros del posfranquismo, Castellote, Madrid, 1977.

Silva Muñoz, F.: Las dimensiones de la reforma politica, Caja de Ahorros de Cádiz, 1974.

Simonet, J. L.: «L'Espagne en transition», en Futuribles, 1977, págs. 163-184.

Sor, A.: «Spagna: verso quale democrazia?», en Politica del Diritto, diciembre 1977, págs. 709-726.

Sol, F.: «L'Espagne bouge», en Revue d'Études Politiques Méditerranéenes, diciembre 1975 , págs. 5-15.

STORY, J.: «Espagne: la liberté peu a peu», en Esprit, septiembre 1977, páginas $95-109$.

- «Le printemps de Madrid», en Politique Etrangère, núm. 1, 1978, págs. 21-57.

SuÁrez, A.: El derecho al futuro, Presidencia del Gobierno, Madrid, 1975.

- Discursos del presidente del Gobierno español (1976-1977), Presidencia del Gobierno, Madrid, 1977.

- Un nuevo borizonte para España, Presidencia del Gobierno, Madrid, 1978.

Subra, P.: «Espagne 1976: la projection du passé sur l'avenir», en Revue Française d'Études Politiques Méditerranéenes, núm. 14, 1976, págs. 24-41.

- L'Espagne ou la démocratie retrouvée, Enaj, París, 1978.

Tamames, R.: A dónde vas, España, Planeta, Barcelona, 1976.

- Un proyecto de Constitución española, Planeta, Barcelona, 1977.

TEzANos, J. F.: «Ante la necesaria apertura de un proceso constituyente en la España actual», en Sistema, núms. 17-18, abril 1977, págs. 3-10.

Tierno Galván, E.: Cabos sueltos, Bruguera, Barcelona, 1982.

URBano, P.: España cambia la piel, Sedmay, Madrid, 1976.

VEGa García, P. de: «La transición política española a la luz de los principios democráticos de legalidad, publicidad y racionalidad», en J. CARPIzo (coordinador), Las experiencias del proceso político constitucional en México y España, Universidad Nacional Autónoma de México, 1979, págs. 247-269. 
VergotinI, G. de (a cura di): Una Constituzione democratica per la Spagna, Franco Angeli Editore, Milán, 1978.

Vidal-Beneyto, J.: «Le revers de la médaille», en Pouvoirs, núm. 8, 1979, páginas $55-61$.

- Diario de una ocasión perdida, Kairós, Barcelona, 1981.

Villar Raso, M.: Una república sin republicanos, Bilbao, 1977.

Villarín, J.: 1974, año Arias. El diario político español, Sedmay, Madrid, 1975. 